\title{
Latest bibliometric factors for the Polish Journal of Neurology and Neurosurgery
}

\author{
Zbigniew K. Wszolek ${ }^{1}$, Łukasz Stolarczyk ${ }^{2}$, Jarosław Sławek ${ }^{3}$ \\ ${ }^{1}$ Co-Editor-in-Chief, Department of Neurology, Mayo Clinic Florida, Jacksonville, Florida, United States \\ ${ }^{2}$ Journal Administrator, Via Medica ${ }^{\mathrm{mx}}$, Gdansk, Poland \\ ${ }^{3}$ Department of Neurology and Psychiatry, Medical University of Gdansk, Poland
}

The latest bibliometric measurements of the Polish Journal of Neurology and Neurosurgery (PJNNS, Neurologia i Neurochirurgia Polska) have recently become available.

The Clarivate Analytics' Impact Factor of the PJNNS increased from 1.025 in 2019 to 1.621 in 2020, and the Elsevier's Cite Score $^{\text {ts }}$ increased from 1.70 in 2019 to 2.30 in 2020 (Fig. 1). The editors of the Journal thank all authors for submitting their work to the PJNNS, and our reviewers for their critical assessment of the submitted manuscripts that led to this substantial improvement in the Journal's standing. We anticipate a further increase in these bibliometric measures in the next year because a number of our COVID-19 papers published in 2020 and 2021 are getting significant attention and are already frequently downloaded and referenced.

Here, we would like to thank the authors of the five most cited articles from the last pre-COVID-19 year of 2019. In that year, the first year in which our Journal was published by Via Medica ${ }^{\mathrm{m}}$, our new publishing house, the most cited manuscript was an Invited Review paper on the role of vitamin D in multiple sclerosis authored by Dr. Halina Bartosik-Psujek and Dr. Marek Psujek from the University of Rzeszow, Poland [1]. The remaining four articles were all Research Papers.

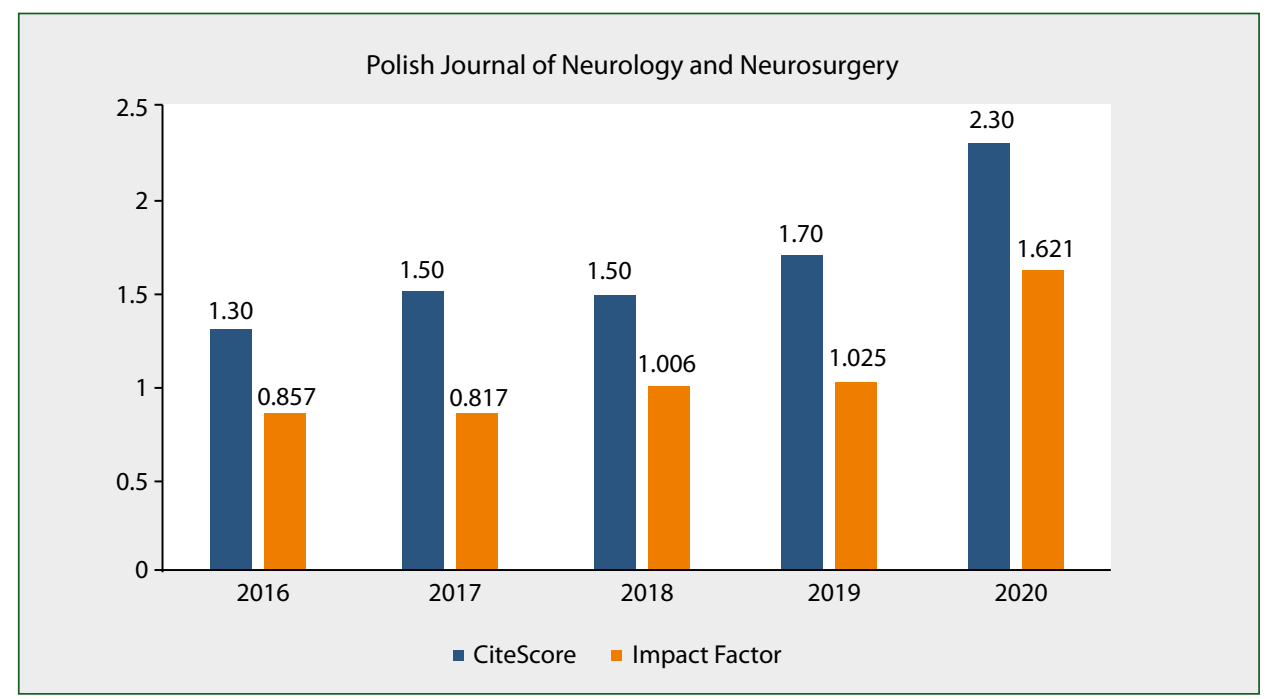

Figure 1. Gradual increases of both CiteScore and Impact Factor, the two most important bibliometric indicators used by Scopus database and Web of Science, respectively. CiteScore 2020 counted the citations received in 2017-2020 to all elements published in the Journal in 2017-2020 and divided this by the number of publications published in 2017-2020. Impact Factor 2020 was calculated by taking the number of citations in 2020 of all items published in 2018 and 2019 in the Journal and dividing that number by the total number of articles and reviews published in 2018 and 2019. An Impact Factor of 1.0 means that, on average, the article published has been cited once in the past two years. An Impact Factor of 2.0 means that, on average, these articles have been cited twice

Address for correspondence: Zbigniew K. Wszolek, M.D., Department of Neurology, Mayo Clinic Florida, 4500 San Pablo Rd, Jacksonville, FL 32224, USA; e-mail: wszolek.zbigniew@mayo.edu 
Among them, the most cited article was an assessment of the relationship between C-reactive protein and albumin ratio on mortality in acute ischaemic stroke patients written by Dr. Mehtap Kocatürk and Dr. Özcan Kocatürk from the Harran University in Sanliurfa, Turkey [2]. The third most cited article, written by Dr. Michał J. Schinwelski, Dr. Emilia J. Sitek, Dr. Piotr Wąż, and Dr. Jarosław Sławek from St. Adalbert Hospital and the Medical University of Gdansk, Poland and from the Neurology Clinic in Tczew, Poland, discussed the prevalence and predictors of post-stroke spasticity and its impact on daily living and quality of life [3]. The fourth manuscript, written by Dr. Gabriela Rusin, Dr. Ewa Wypasek, Dr. Elżbieta Papuga-Szela, Dr. Joanna Żuk, and Dr. Anetta Undas from Jagiellonian University Medical College in Krakow, Poland, provided data on oral anticoagulants in the treatment of cerebral venous sinus thrombosis [4]. The fifth and final manuscript, written by Dr. Edyta Krajczy, Dr. Marcin Krajczy, Dr. Jacek Luniewski, Dr. Katarzyna Bogacz, and Dr. Jan Szczegielniak from the Municipal Hospital in Nysa, Poland, and from the Opole University of Technology in Opole, Poland, assessed the effects of dysphagia therapy in patients in the early post-stroke period [5].
The Editors congratulate all of the authors whose manuscripts were published in PJNNS for their important contributions to science.

\section{References}

1. Bartosik-Psujek H, Psujek M. Vitamin D as an immune modulator in multiple sclerosis. Neurol Neurochir Pol. 2019; 53(2): 113-122, doi: 10.5603/pjnns.a2019.0015.

2. Kocatürk M, Kocatürk Ö. Assessment of relationship between C-reactive protein to albumin ratio and 90-day mortality in patients with acute ischaemic stroke. Neurol Neurochir Pol 2019;53(3):205-211, doi: 10.5603/PJNNS.a2019.0020.

3. Schinwelski M, Sitek E, Wąż P, et al. Prevalence and predictors of poststroke spasticity and its impact on daily living and quality of life. Neurol Neurochir Pol. 2019; 53(6): 449-457, doi: 10.5603/pjnns.a2019.0067.

4. Rusin G, Wypasek E, Papuga-Szela E, et al. Direct oral anticoagulants in the treatment of cerebral venous sinus thrombosis: a single institution's experience. Neurol Neurochir Pol. 2019; 53(5): 384-387, doi: 10.5603/PJNNS.a2019.0037.

5. Krajczy E, Krajczy M, Luniewski J, et al. Assessment of the effects of dysphagia therapy in patients in the early post-stroke period: a randomised controlled trial. Neurol Neurochir Pol. 2019; 53(6): 428434, doi: 10.5603/pjnns.a2019.0053. 